\title{
Cantons de Villefranche-de-Rouergue et Villeneuve (Aveyron)
}

\section{OpenEdition}

\section{Journals}

Édition électronique

URL : http://journals.openedition.org/adlfi/10429

ISSN : 2114-0502

Éditeur

Ministère de la culture

Référence électronique

"Cantons de Villefranche-de-Rouergue et Villeneuve (Aveyron) ", ADLFI. Archéologie de la France -

Informations [En ligne], Midi-Pyrénées, mis en ligne le 01 mars 1997, consulté le 03 mai 2019. URL :

http://journals.openedition.org/adlfi/10429

Ce document a été généré automatiquement le 3 mai 2019.

(C) Ministère de la Culture et de la Communication, CNRS 


\section{Cantons de Villefranche-de- Rouergue et Villeneuve (Aveyron)}

Date de l'opération : 1990 - 1991 (PR)

Inventeur(s) : Bénévent Christian

1 Ces deux cantons, riches en gisements préhistoriques,avaient été délaissés par les historiens et souffraient d'un état des connaissances qu'il convenait d'actualiser compte tenu des impératifs de la carte archéologique et d'un projet de déviation sur la commune de Villefranche-de-Rouergue. En effet, sur les dix-sept communes de ces deux cantons, seules six étaient mentionnées dans les inventaires du XXe $s$. avec des imprécisions topographiques qui justifiaient une reprise de la documentation.

2 À l'issue de ces deux années de prospections, vingt-sept gisements ont pu être répertoriés et sont, pour leur plus grande part,inédits : tumulus protohistoriques (Âge du bronze, Âge du fer) à Savignac, La Borie-Grande ; Martielk, Puech des Prunes (dix-sept tumulus de $4 \mathrm{~m}$ à $18 \mathrm{~m}$ de diamètre à proximité d'un dolmen) et Puech-d'Alès (cinq tumulus de $6 \mathrm{~m}$ à $16 \mathrm{~m}$ de diamètre à proximité d'un dolmen).

Les établissements gallo-romains sont nombreux, marqués par l'abondance des débris de toitures (tegulae et imbrices), d'éléments de construction (moellons, mortier de béton de chaux), mais aussi par des céramiques (sigillées sud-gauloises, communes, amphores Dr. 20, sigillées claires, verreries, estampées) qui permettent d'établir des bases chronologiques comprises entre le $\mathrm{I}^{\mathrm{er}} \mathrm{s}$. et le IV ${ }^{\mathrm{e}} \mathrm{s}$. après J.-C. : Savignac, La Rode-Haute, La Garrigue, La Pradelle, Gournac, Camp-del-Mouly, Claux-de-Parrouty, Algouse-Haute ; Villefranche-de-Rouergue, La Borie-des-Pères (il s'agit d'une mention ancienne de 1828, avec statuaire, lapidaire, bijoux, céramiques, etc.), complétées par des indices matériels (amphores vinaires italiques Dr.1, céramiques à vernis noir du type campanienne $\mathrm{A}$, céramiques communes, etc.) attestant une occupation antérieure comprise, semble-t-il, entre le début du $\mathrm{I}^{\mathrm{er}}$ s. et la fin du II $\mathrm{e}$ s. avant J.-C. (?), encore à Savignac, l'Auzeral (Gallia, 1974 : 405), Les Fontanelles, Maillard, Les Cayrouses-Haute, Filhol, Craissac, Le Puech-deCénac. 
D'autres, en revanche, ont fait l'objet de réaffectations partielles : nécropoles du Haut Moyen Âge ou du Moyen Âge à Savignac, Le Pradal et Villefranche-de-Rouergue, La Madeleine (Gallia,1964 : 435).

Plusieurs nécropoles, semble-t-il,isolées ont encore été décelées à Ols-et-Rinhodes, le Puech-de-la-Guise (sépultures en coffres et en sarcophages), à Sainte-Croix (sarcophages dont un à logette céphalique, coffres en dalles), à Villefranche-de-Rouergue, Les Gravasses (sarcophages en grès trapézoïdaux) et Saint-Mémory (sarcophages, coffres en dalles, tombe en batière sous tegulae). Reste encore à signaler, une motte castrale à Savignac, La Motte, et une mine de plomb argentifère à Villefranche-de-Rouergue, Le Trou-de-Caldéron (Gallia,1986:315).

\section{INDEX}

Index chronologique : Âge du Bronze, Âge du Fer, Empire romain, ép médiévale operation prospection (PR) 